\title{
An Integrated \& Inquiry-based Approach to Exploring Plant Metabolism
}

\author{
John S. Peters \\ College of Charleston, Biology, 66 George St, Charleston SC 29424 USA \\ (PetersJ@cofc.edu)
}

\begin{abstract}
Many introductory biology textbooks, and consequently classes, largely teach photosynthesis and cellular respiration as separate metabolic processes. The consequence is that students often fail to understand the important connections between these metabolic processes within plants, leading to the common misconception that "animals do respiration, and plants do photosynthesis". This workshop went outside to explore these connections. We used carbon dioxide gas sensors to estimate leaf NPP, and using more studentdirected learning approaches, developed procedures for estimating GPP and respiratory rates. Ideally, this lab sets the methodological and observational context for a student-directed inquiry-based independent project in which students explore questions related to how genetic, developmental, or environmental factors influence leaf metabolism and therefore productivity. This workshop discussed ways to structure this independent project to encourage collaboration and foster scientific intellectual skills, and a general spirit of scientific inquiry. At the end you will be 'ABLE' (sorry I couldn't help myself) to explore an entire introductory biology curriculum, which uses an inquiry-based learning framework.
\end{abstract}

Keywords: photosynthesis, cellular respiration, leaf metabolism, inquiry learning

\section{Mission, Review Process \& Disclaimer}

The Association for Biology Laboratory Education (ABLE) was founded in 1979 to promote information exchange among university and college educators actively concerned with teaching biology in a laboratory setting. The focus of ABLE is to improve the undergraduate biology laboratory experience by promoting the development and dissemination of interesting, innovative, and reliable laboratory exercises. For more information about ABLE, please visit http://www.ableweb.org/.

Advances in biology laboratory education is the peer-reviewed publication of the conference of the Association for Biology Laboratory Education. Published articles and extended abstracts are evaluated and selected by a committee prior to presentation at the conference, peer-reviewed by participants at the conference, and edited by members of the ABLE Editorial Board. Published abstracts are evaluated and selected by a committee prior to presentation at the conference.

\section{Citing This Article}

Peters JS. 2020. An integrated \& inquiry-based approach to exploring plant metabolism. Article 47 In: McMahon K, editor. Advances in biology laboratory education. Volume 41. Publication of the 41st Conference of the Association for Biology Laboratory Education (ABLE). https://doi.org/10.37590/able.v41.abs47

Compilation (C) 2020 by the Association for Biology Laboratory Education, ISBN 1-890444-17-0. All rights reserved. No part of this publication may be reproduced, stored in a retrieval system, or transmitted, in any form or by any means, electronic, mechanical, photocopying, recording, or otherwise, without the prior written permission of the copyright owner.

ABLE strongly encourages individuals to use the exercises in this volume in their teaching program. If this exercise is used solely at one's own institution with no intent for profit, it is excluded from the preceding copyright restriction, unless otherwise noted on the copyright notice of the individual chapter in this volume. Proper credit to this publication must be included in your laboratory outline for each use; a sample citation is given above. 